\title{
ECONOMIC CHALLENGES OF DRUG POLICY IN GEORGIA
}

\author{
DOI: 10.17261/Pressacademia.2019. 1169 \\ RJBM-V.6-ISS.4-2019(9)-p.320-325
}

\section{Lali Khurtsia ${ }^{1}$, Vano Tsertsvadze ${ }^{2}$}

${ }^{1}$ Iv. Javakhishvili Tbilisi State University. 1, Chavchavadze Ave., 0179 Tbilisi, Georgia. lali.khurtsia@tsu.ge, ORCID: 0000-0002-1749-4866

${ }^{2}$ Georgian Institute of Public Affairs ( GIPA ), 9, letim Gurji st. 0105 Tbilisi, Georgia. v.tsertsvadze@gipa.ge, ORCID: 0000-0003-3546-860X

\section{To cite this document}

Khurtsia, L., V. Tsertsvadze, (2019). Economic challenges of drug policy in Georgia. Research Journal of Business and Management (RJBM), V.6(4), p.320-325

Permemant link to this document: http://doi.org/10.17261/Pressacademia.2019.1169

Copyright: Published by PressAcademia and limited licenced re-use rights only.

\begin{abstract}
Purpose - Georgian drug policy in last dacades can be charachterized as a strong prohibitive policy. Application of restrictive sanctions are accompanied by imprisonment or monetary fines. Punishment policy is an economic incentive which aimes to reduce the level of drug use and the harm caused by it.

In this paper, we examine how the drug market responds to restrictive policies. We analyze government supported incentives for 20 years and their impact on drug distribution. Our analysis shows that such a policy does not lead to the reduction in consumption. Baning certain types of drugs causes the demand to responds by switching to alternative substances. Thus in this article, we examine how the drug market responds to prohibitive policies and explain why there is no effect on the level of drug demand during observed period.

Methodology - The article reviews the current situation on the Georgian drug market in light of the economic forces operating there. The work mainly uses review approach. It combines various research findings that have been done over the last 20 years. Changes in drug demand and supply are presented as economic models.

Findings- Research findings show that drug circulation, like any other goods and services, is managed by the principles of economics and the market. In addition to the usual supply and demand that determines the price and quantity of drugs on the black market, it also responds instantly to incentives, including prohibitions and sanctions. Comparative analyses of the secondary data show decreased effectiveness of the Ministry of Internal Affairs while the incidence and prevalence of intravenous users are increasing. The decreased presure from the law enforcements may explain the increased demand on heroin and subotoxin, as well as on hallucinogens and new psychoactive substances in contemporary days.

Conclusion- Drug policy in Georgia, which is based on prohibitive approach is ineffective. The volume of drugs available on the market is determined by the increasing demand in recent years. Steps to reduce supply are forcing suppliers and consumers to look for efficient and safe ways to meet their needs.
\end{abstract}

Keywords: Illicit drugs, prohibition, drugpolicy, decriminalization, substances JEL Codes: J16, M50, M54

\section{INTRODUCTION}

Government drug policy in general can be described in two ways - the application of prohibitive sanctions against drug market implying impisonment and monetary fines to drug users and suppliers and so-called humane approach that includes prevention, treatment and other methods, including decriminalization and liberalization policies. Regardless of the fundamental difference, both drug policies have one common goal - to reduce the harm caused by drug use. Accordingly, any decision to pursue a particular policy should be based on a comparison of the estimated costs and benefits (damage) that may arise as a result of the implementation of these policies. In this article we discuss the impact of prohibitive policies on changes in drug use 
Circulation of illicit drugs as well as any goods are managed by the principles of economics and the market. Besides of usual demand and supply forces, which define the price and amount of distributed drugs on the black market, market immediately reacts upon stimulus, including prohibitions and sanctions.

If we take a look at the trends of drug use in Georgia, the following dynamics can be observed: from the beginning of 90th opium, so called "black", was predominated on black market. The "black" was widely widespread in the countries of former Soviet Union, especially in those regions, where the wild poppy grew. From the end of 90th to 2003-2004 years the portion of heroine was gradually increasing. These were the years of prosperity for the drugs market, because the handmade drugs were substituted by heroine manufactured with more sophisticated technology and distributed under the unofficial support by the law enforcement representatives.

In 2003, when the authority of rose revolution reformed law enforcement system and the ways through which Georgian drug users got heroine were locked. Considering that demand for drugs is sufficiently inelastic with respect to outward factors changing, which means that demand on drugs insignificantly changes in the conditions of price increasing or/and restriction of police pursuing, drug users started consuming homemade opioids got from confectionery poppy seeds

Shortly after, the authority prohibited this product, it was totally removed from trading chain and during 2004-2008 demand on drugs was changed again - homemade drugs were substituted by injection drugs made from subotex pills (Report 2012) containing buprenorphine illegally imported from different countries of Europe (Burchuladze, 2011).

These years are characterized by anti-drug campaign. In 2006 zero tolerance was declared towards drug users and massive inspections were begun in the streets on the bases of reasonable doubt (Vardiashvili 2013). According to another research, in 2008, 45000 people were detained as a result of this campaign, the proceeding was started over 30000 people concerning to drug usage (Otiashvili at all 2011).

\section{DEMAND SHIFTING AND SUBSTITUTES}

Such drastic deterioration of situation on the Georgian drug market put forward the significance of substitutes. The users started consuming homemade injecting drugs. In 2008-2009 handmade stimulators were used, which were made from cough medicines containing ephedrine, which could be bought in the country pharmacies without a prescription. (Otiashvili, 2008). Slangy name of such drug was "Vint" in Georgia, which is characterized by long-lasting effect. In this period, also well forgotten old handmade drug "Jeff" was spread out, which also used ephedrine and the drug was made by the way of chemical reaction with potassium permanganate. Unlike Whitt, Jeff is a short-acting stimulant. Medicines containing Ephedrine have been banned since 2011 (Alavidze et al., 2015) , potassium permanganate was removed from the trading chains (Parliament of Georgia, 22/05/2012). However, during the same period, the codeine-containing drug called "crocodile" was added to the range of easily accessible handmade injection spectrum (Sikharulidze, 2012).

In 2014 pharmacy drug addiction was significantly restricted as a result of tightening of prescription procedures. As a result supply of drugs on Georgian black market was extremely reduced, though drugs were still was on demand. The demand on drugs could only be satisfied by "crocodile" (Alavidze et al., 2016), which was a very devastating drug for human body, besides that, consuming "crocodile" was related to the serious neurological disorders and atrophy of human organs (that's where the name "crocodile" comes from) the overdosing risk caused by it was very high (Sikk, 2007);

Figure \#1 reflects the results of various studies conducted in 2009-2017. This figure clearly shows the changes that the subutex black market has undergone. The increased activity of the law enforcement system initially led to a decrease in the availability of this illegal substance on the market. In economic terms, these steps were directed to restrict supply of drugs on the market. Although, market demand remained unchanged and "Vint" and "Jeff" replaced Subutex. In 2012, some chemicals and medicines containing ephedrine were banned - these steps were still directed to reduce supply. But again, the demand for medicines has not decreased, and since 2012 even more dangerous drug - "crocodile" has come into circulation. The only drug substance that remained unchanged for many years was heroin with its high consumption rate, a large share of which was in western Georgia, including Batumi in which neighbourhood of Turkey probably has been playing an important role. (Curatio, International Foundation; Bemoni, Public Union, 2013) . 
Figure 1: Injection of Drugs

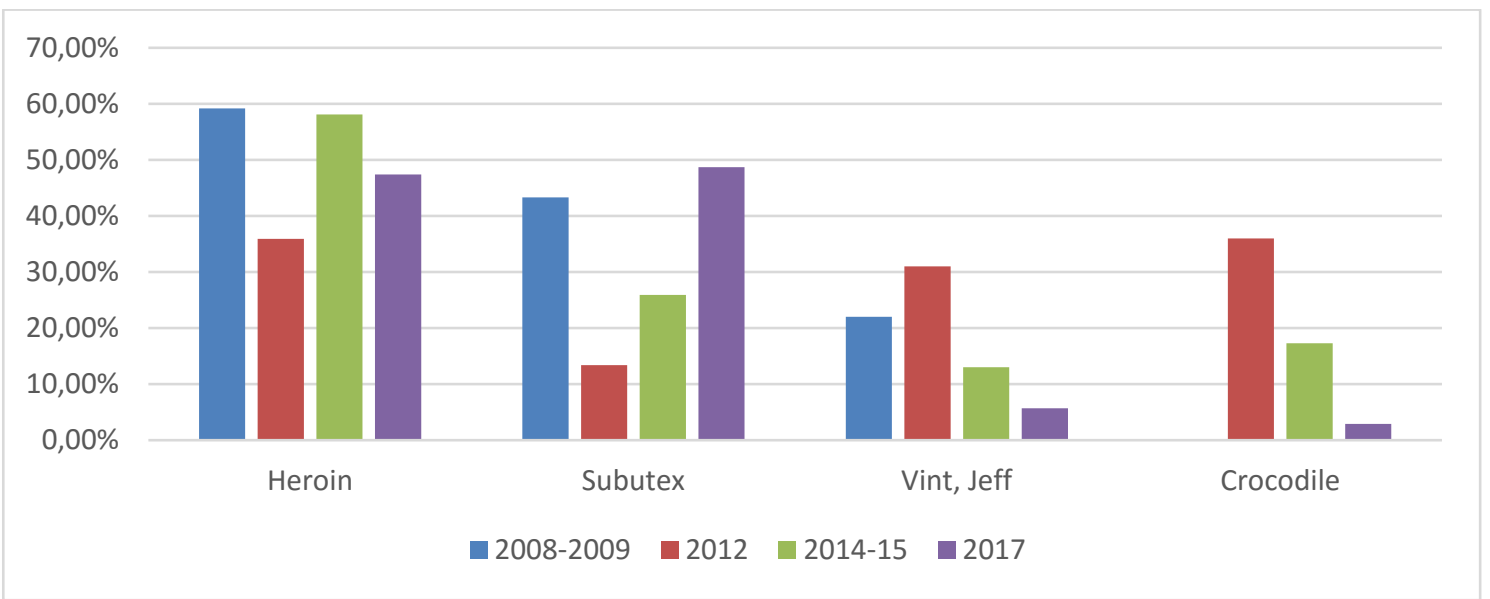

Source: (Curatio, International Foundation; Bemoni, Public Union, 2009); (Curatio, International Foundation; Bemoni, Public Union, 2013); (Curatio, International Foundation; Bemoni, Public Union, 2015); (Curatio, International Foundation; Bemoni, Public Union, 2017)

In a study published in 2015, we pointed out and predicted that drug restriction policies in the market would not affect drug demand reduction and that drug users could adapt to new conditions by finding new drugs based on market restrictions. We noted that the tightening of the pharmacy prescription after 2014 will create new stimulus for the illegal drug market. A gradual decrease in pharmacy drug addiction and the reduction of crocodile consumption would begin, the cause of latter would be premature death of consumers and, probably, the use of heroin would remain unaffected. (Khurtsia \& Tsertsvadze, 2015)

Subsequent years have shown that the market has been completely reacted according to the laws of economics, and as seen in Figure \# 1 by 2017, heroin still holds the leading position among the most commonly used intravenous drugs, although the most commonly used drug is buprenorphine. In contrast, the use of ephedrine ("Jeff", "Whitt") and dezomorphine ("Crocodile") containing drugs were decreased due to increased availability of heroin and subutex.

The same trend, in particular the policy of supply reduction, is also observed in the market of non-injection drugs. The following figure \# 2 shows how the demand for pharmacy drug addicts (depressants) changed in 2009-2012, when supply of narcotic analgesics and hallucinogens was restricted. Since 2012, depressants have been on the leading positions in noninjection drug use, though tightening pharmacy prescription rules have led to declining consumption trend (from $74.8 \%$ in 2012 to $69 \%$ in 2015). However, since 2015, we have witnessed the emergence of new psychoactive substances. It is noteworthy that if the share of injecting drug users had previously been low in non-injecting drug use, by 2015 a large proportion of injecting drug users have used non-injectable drugs (82.2\%). At the same time, the share of new psychoactive drugs, which are consumed through smoking (synthetic marijuana, bio, spas), has doubled.

It is critical to note that the spread of new psychoactive substances was facilitated by the Internet and online payment systems. The use of new technologies in the drug market reaches a large scale. According to articles published in local media, the supplier and the consumer are connected to each other using information technologies and agree on price and place of purchase of drugs. Payments are usually made through international remittances. Such a scheme ensures the security and inaccessibility of the supplier from the law inforcement structures. 
Figure 2: Non-injectable Drug Use

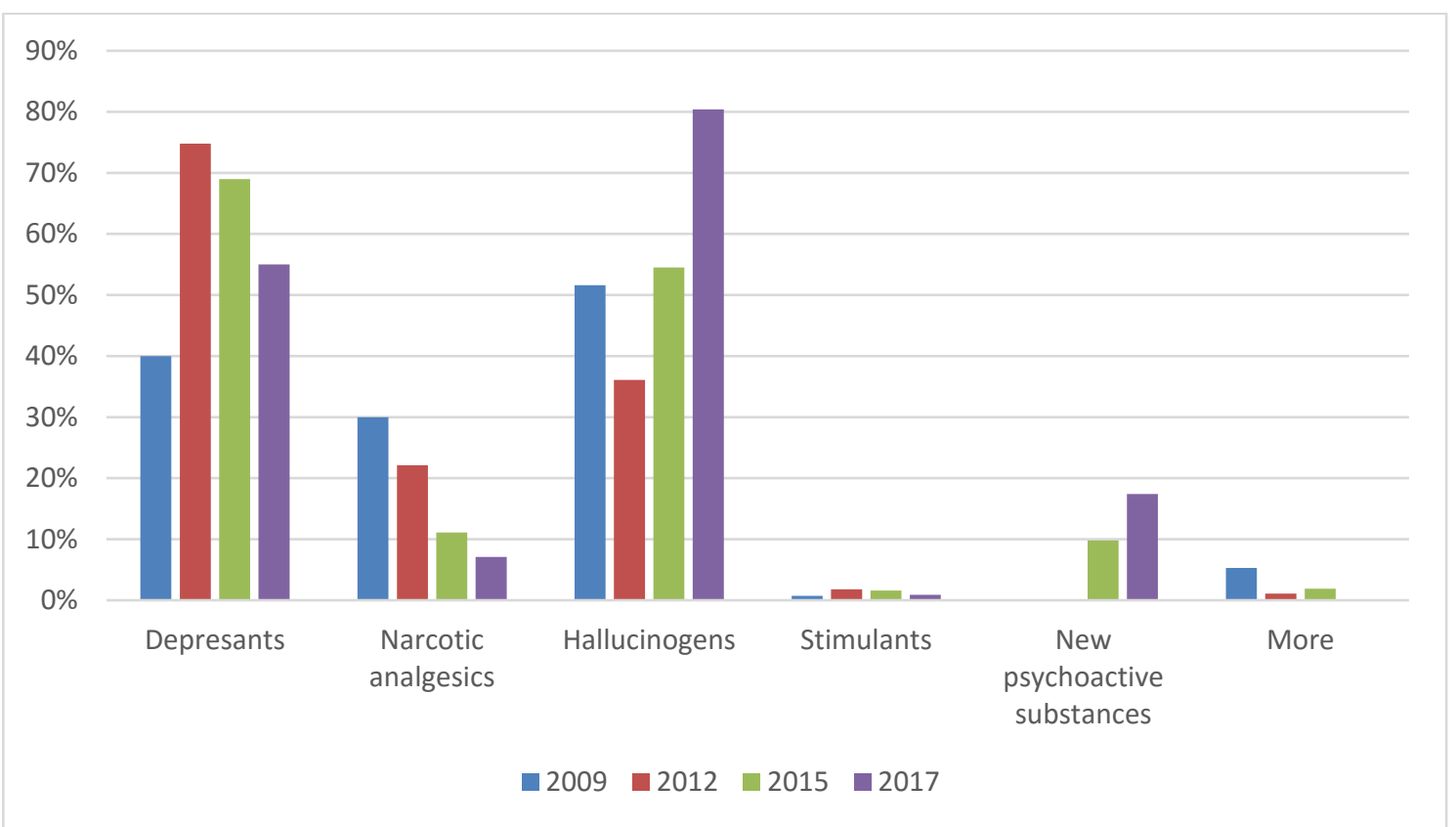

Source: (Curatio, International Foundation; Bemoni, Public Union, 2009) ; (Curatio, International Foundation; Bemoni, Public Union, 2013) ; (Curatio, International Foundation; Bemoni, Public Union, 2015) ; (Curatio, International Foundation; Bemoni, Public Union, 2017)

\section{SECONDARY DATA ANALYSES}

Despite government restrictions on the drug market, the number of drug users in Georgia is gradually increasing. Studies conducted to evaluate the pool of problem injecting drug users in 2009-2017 revealed a significant increase. In 2009, using the multiplier method and consensus with field experts, the number of problematic injecting drug users in Georgia was estimated at 40,000, with a prevalence of 1.5\% (Sirbiladze, 2010). In 2012, different method was used for the assessment, and the number of users increased to 45,000 (prevalence 1.65\%) (Sirbiladze, 2013). Despite the increase in indicators, experts have refrained from validating this trend as different methodologies have been used (Alavidze et al., 2015).

In the following 2014 and 2016, the Bemoni Society and the International Foundation Curatio carried out an assessment of the population of injecting consumers using two measurement methods - they estimated the scale of the network and measured the multiplier coefficients and calculated measurement indicators. Both studies were followed by expert consensus and the number of injecting drug users was defined (BPU \& CIF, 2015, 2017 ). The results of all four studies are summarized in Table \# 1 below.

Table 1: Number and Prevalence of Injecting Drug Users in 2009-2016

\begin{tabular}{|c|c|c|}
\hline Years & Injecting drug users & Prevalence among injecting drug users \\
\hline 2009 & 40,000 & $1.50 \%$ \\
\hline 2012 & 45,000 & $1.65 \%$ \\
\hline 2014 & 49700 & $2.02 \%$ \\
\hline 2016 & 52500 & $2.24 \%$ \\
\hline
\end{tabular}

On the other hand Ministry of Internal Affairs annualy publishes its report about recorded criminal cases. Statistical analyses retrieved from the MIA shows a decline in drug crime during the period of 2014-17 (see table \#2 below). Data published on the MIA's website reflects cases registered and opened under Articles 260-274 of the Criminal Code. It is noteworthy that in 2017, compared to 2014, the number of drug offenses decreased by $34.87 \%$. In 2017, 1998 cases of illegal production, purchase, storage, shipment, transfer and / or use of drugs were detected (article 273 of the Criminal Code). This indicates 
that by the effort of the law enforcements only $4 \%$ of those drug users were identified, the number of which was revealed in the study of Bemoni Society and the International Foundation Curatio (BPU \& CIF, 2016, 2017).

Comparative analyses of the statistical data of the MIA and Curatio and Bemoni study (it should be mentioned that prior to 2017, both injecting and non-injecting drug use was illegal according to article 273 of the Criminal Code), shows the number of crimes reported in accordance with Article 273, and thus the effectiveness of the Ministry of Internal Affairs is decreasing while the incidence and prevalence of intravenous users are increasing. As these two should correlate with each other this finding demonstrates the following options: either the efficiency of the Ministry of Internal Affairs has decreased, and this institution is not able to maintain effective control over drug use, or high-profile cases in recent years (the case of Beka Tsikarishvili, decisions of the Constitutional Court) have affected the current drug policy and the oppression of drug use is no longer among priorities of contemporary public policy in Georgia.

On the one hand, the number of registered crimes for smuggling and purchasing of psychotropic substances has not been reaching even 100 cases per year, on the other hand the use of new psychotropic substances started in 2015 increased by $7 \%$ in 2017, this directly indicates how the role of the Ministry of Internal Affairs uneffective during this period. The decreased presure from the law enforcements may explain the increased demand on heroin and subotoxin, as well as on hallucinogens and new psychoactive substances in contemporary days.

The reviewed data indicates that drug circulation in Georgia is governed by the basic principles of a market economy. Drug policy directed toward destimulation of supply is ineffective. The number of drugs available in the market is determined by the increasing demand in recent years. Steps to reduce supply are forcing suppliers and consumers to look for efficient and safe ways to meet their requirements.

Table 2: Registered Drug Offenders in Georgia (2014-2017)

\begin{tabular}{|c|c|c|c|c|c|c|}
\hline & 2014 & 2015 & 2016 & 2017 & \multicolumn{2}{|c|}{$\begin{array}{l}\text { Crime changes in } 2017 \text { in } \\
\text { comparison with } 2014 \text { as a base }\end{array}$} \\
\hline Articles of CC & & & & & $\mathbf{n}$ & $\%$ \\
\hline Drug Crime 260-274 & 7312 & 5126 & 5196 & 4762 & -2550 & $-34.87 \%$ \\
\hline $\begin{array}{l}\text { Heavy - 260, 261-III-IV, 262, 263-III- } \\
\text { IV, 264-II-IV, 265-II-III, 266. 267. 268- } \\
\text { II-III, 271-III-IV, 272-II-III. }\end{array}$ & 3087 & 2424 & 2887 & 2636 & -451 & $-14.61 \%$ \\
\hline Drug smuggling 262 & 323 & 272 & 248 & 200 & -123 & $-38.08 \%$ \\
\hline $\begin{array}{l}\text { Purchase, storage or sale } \\
\text { of drugs } 260\end{array}$ & 2737 & 2112 & 2473 & 2327 & -410 & $-14.98 \%$ \\
\hline $\begin{array}{l}\text { Psychotropic drugs smuggling } \\
263\end{array}$ & 27 & 32 & 27 & 20 & -7 & $-25.93 \%$ \\
\hline $\begin{array}{l}\text { Purchase, storage, sale } \\
\text { of psychotropic means } 261\end{array}$ & 88 & 85 & 96 & 79 & -9 & $-10.23 \%$ \\
\hline $\begin{array}{l}\text { Illegal sowing } \\
\text { of plants containing drugs } 265\end{array}$ & 153 & 155 & 178 & 128 & -25 & $-16.34 \%$ \\
\hline Substance use 273 & 3978 & 2462 & 2165 & 1998 & -1980 & $-49.77 \%$ \\
\hline All the others $264,266-272,274$ & 6 & 8 & 9 & 10 & 4 & $66.67 \%$ \\
\hline
\end{tabular}

Source: MIA web site: http://police.ge/en/useful-information/statistics/skhvadaskhva-sakhis-statistika-kvlevebi

\section{FINDINGS}

As indicated above, study analyses show that drug circulation, like any other goods and services, is managed by the principles of economics and the market. In addition to the usual supply and demand that determines the price and quantity of drugs on the black market, it also responds instantly to incentives, including prohibitions and sanctions. Comparative analyses of the secondary data shows decreased effectiveness of the Ministry of Internal Affairs while the incidence and prevalence of intravenous users are increasing. The decreased presure from the law enforcements may explain the increased demand on heroin and subotoxin, as well as on hallucinogens and new psychoactive substances in contemporary days. 
It should be noted that according to another research findings (Bergen-Zico et al., 2017), the costs required to implement a punitive policy did not lead to behavioral changes in the career of drug addicts, thus confirming the ineffectiveness of such policies. One of the main objectives of this study was to determine whether punitive measures would prevent drug addicts from stopping the use of illegal substances. The results showed that the majority of respondents resumed drug use three months after the judgment, and they all returned to drugs 11 months later. This finding is an important indicator of how crucial the study is to evaluate policy effectiveness.

\section{CONCLUSION}

From this review we can conclude that drug policy directed toward destimulation of supply is ineffective. The number of drugs available in the market is determined by the existing demand on drugs. Steps to reduce supply are forcing suppliers and consumers to look for efficient and safe ways to meet their requirements and as a result demand is shifted to other substances thus substituting current demand with new (or old) ones.

Therefore, before the government starts any preventative policy, policymakers should analyse other factors which maith have even more influential features than punishment and the risk of beeng imprisoned. So the question still remains - what determines consumption, what causes the inelastic nature of drug use, and whether the drug policy based on decriminalization and liberalization is an effective alternative to reduce the harm?

\section{REFERENCES}

Bergen-Cico, D., Otiashvili, D., Kirtadze, I., Zebransky, T., \& Tsertsvadze, V. (2017). Cost analysis of Georgia's street level drug testing policy. Journal of Drug Policy Analysis 10 (2) , p. 1-22.

BPU, BP, \& CIF, Cl (2015). Population Size Estimation of People Who Inject Drugs in Georgia 2014. Tbilisi: CIF, p. 1-51

BPU, BP, \& CIF, CI (2017). Population Size Estimation of People Who Inject Drugs in Georgia 2016. Tbilisi: CIF. p. 1-54

Curatio, International Foundation; Bemoni, Public Union. (2009). Bio-behavioral surveillance surveys among injecting drug users in Georgia (Tbilisi, Batumi, Zugdidi, Telavi, Gori, 2008 - 2009). study report. Tbilisi: CIF p. 1-160.

Curatio, International Foundation; Bemoni, Public Union. (2013). HIV risk and prevention behaviors among People who inject drugs in six cities of Georgia Bio-behavioral surveillance survey in Tbilisi, Batumi, Zugdidi, Telavi, Gori, Kutaisi in 2012. Tbilisi: CIF, p.1-130.

Curatio, International Foundation; Bemoni, Public Union. (2015). HIV risk and prevention behaviors among People Who Inject Drugs in seven cities of Georgia. Bio-Behavioral Surveillance Survey in seven cities of Georgia. Tbilisi: CIF p.1-58.

Curatio, International Foundation; Bemoni, Public Union. (2017). HIV Risk and Prevention Behaviors Among People Who Inject Drugs in Seven Cities of Georgia Integrated Bio-Behavioral Surveillance Survey in seven cities of Georgia. Tbilisi: CIF p.1-156.

Khurtsia, L., \& Tsertsvadze, V. (2015). Drugs, Silk Road, Bitcoins. World Academy of Science, Engineering and Technology, International Science Index, Economics and Management Engineering (pp. 9 (7), 1529). Istanbul: WASET.

Otiashvili, D., Kirtadze, I., Tsertsvadze, V., Chavchanidze, M., \& Zabransky, T. (2012). How Effective Is Street Drug Testing. Tbilisi: Alternative Georgia. Tbilisi: altgeorgia, p. 1-39.

Sirbiladze, T. (2010). Estimating the prevalence of injecting drug use in Georgia: Consensus report. Tbilisi: Bemoni Public Union, p. 1-90.

Sirbiladze, T. (2013). Estimating the prevalence of injecting drug use in Georgia: Consensus report. GFATM, p. 1-91.

Alavidze, S., Balanchivadze, N., Batselashvili, L., Duchidze, N., Javakhishvili, J., Kikvidze, T., Tsertsvadze, V. (2015). Drug Situation in Georgia. Annual Report 2013. Tbilisi: Alternative Georgia, p.1-44

Alavidze, S., Duchidze, N., Kirtadze, I., Otiashvili, D., Razmadze, M., Sturua, L., Javakhishvili, J. (2016). Drug Situation in Georgia. Tbilisi: Alternative Georgia, p.1-44.

Burchuladze, n. (06 06 2011). Poppy Case. The Kviris Palitra magazine. p. 11.

The Parliament of Georgia. (22/05/2012). The Law of Georgia on Narcotic Drugs, Psychotropic Substances and Precursors, and Narcological Assistance. Tbilisi: Legislative Herald of Georgia, p. 1-20.

Javakhishvili, J., Balanchivadze, N., Kirtadze, I., Sturua, L., Otiashvili, D., \& Zabrasnicki, T., (2012). Drug Situation in Georgia. Tbilisi: Alternative Georgia, p. 1-24. 